\title{
Aspectos epidemiológicos, patogénicos, clínicos y diagnósticos de la dermatitis atópica. ¿Es posible la prevención?
}

\author{
L. Bagazgoitia, M. Gutiérrez, C. García Blesa, A. Hernández Martín, A. Torrelo \\ Servicio de Dermatología. Hospital Infantil del Niño Jesús. Madrid.
}

Rev Pediatr Aten Primaria. 2009; I I Supl I5:s3 I-s47

Ángela Hernández Martín, ahernandez_hnj@yahoo.es

\section{Resumen}

La prevalencia de la dermatitis atópica (DA) se ha triplicado en los últimos 30 años en los países industrializados. A menudo existen datos de agregación familiar, lo que indica una marcada predisposición genética en estos pacientes. La incidencia es similar en ambos sexos, pero existen diferencias étnicas y geográficas muy significativas que sugieren la participación de factores ambientales en la aparición de la enfermedad. Para entender la fisiopatología de la DA hay que tener en cuenta simultáneamente las anomalías genéticas, la debilidad de la barrera cutánea, la alteración del sistema inmune y la susceptibilidad a padecer sobreinfecciones microbianas de los individuos afectados.

Dado que los mecanismos fisiopatológicos no están bien esclarecidos, de momento no es posible modificarlos para cambiar el curso de la enfermedad. Así, el retraso de la lactancia artificial, la introducción de los alimentos sólidos en el lactante, o las restricciones dietarias en las gestantes afectas de la enfermedad, no han demostrado ser eficaces en la prevención de la DA. Sin embargo, sí parece importante realizar un tratamiento adecuado de las lesiones cutáneas para prevenir la sensibilización alérgica percutánea y evitar la aparición de asma o rinoconjuntivitis.

El picor y la recurrencia de las lesiones son los datos clínicos esenciales. El diagnóstico de la enfermedad suele ser sencillo, pero en algunas ocasiones el pediatra puede requerir ayuda especializada para confirmar el diagnóstico o tratar los casos más severos.

Palabras clave: Dermatitis atópica, Barrera epidérmica, Inmunidad innata, Marcha atópica.

Abstract

The prevalence of atopic dermatitis (AD) has doubled or three-folded in industrialized countries. There are often data of family history of atopic diathesis, suggesting that there is a genetic predisposition in these patients. The incidence is similar in both sexes, but the significant ethnic background and geographic differences point out the importance of environmental factors in the development of the disease.

To understand the physiopathology, it is necessary to take into account genetic abnormalities, dermal barrier impairment, immune system disturbances and the increased suscep- 
tibility of DA patients to suffer from microbial infections. Given that the immunopathological mechanisms of $A D$ are not yet well understood, it is impossible to modify them to change the course of the disease. For example, delaying artificial lactation or the timing of introduction of solid food, as well as performing dietary restrictions in pregnant women, have not shown to have a protective effect in $A D$. However, it seems to be important to treat Cutaneous lesions to prevent allergic sensitization through the skin, which might lead to asthma or rhinoconjuntivitis in these patients.

Pruritus and recurrences are the clinical hallmark of the disease. The diagnosis is usually made straightforward based on clinical features, but the pediatrician may need specialized help occasionally, either to confirm the diagnosis or to manage severe cases.

Key words: Atopic dermatitis, Epidermal barrier, Innate immunity, Atopic march.

\section{Epidemiología}

La prevalencia de la dermatitis atópica (DA) en la población general es difícil de precisar, pero se calcula que en los países desarrollados entre el $15 \%$ y el $30 \%$ de los niños sufren la enfermedad. Un $60 \%$ de los casos son diagnosticados antes del año de edad, y en torno al $85 \%$ debutan antes de los 5 años de vi$\mathrm{da}^{1}$. En las últimas tres décadas se han doblado e incluso triplicado las cifras de pacientes afectados, constituyendo un importante problema de salud pública a nivel mundial.

La incidencia es similar en ambos sexos, pero existen diferencias étnicas y geográficas muy significativas que sugieren la participación de factores ambientales en la aparición de la enfermedad. Por otro lado, existen datos de agregación familiar, de tal forma que la prevalencia de DA en niños con familiares de primer y segundo grado afectos puede llegar a ser del 39\% y del 19\% respectivamente ${ }^{2}$. Todo ello es indicativo de una marcada predisposición genética sobre la que actúan factores ambientales que modulan el desarrollo de la enfermedad.

\section{Variaciones geográficas}

La prevalencia de la DA es mucho mayor en países industrializados como Estados Unidos, Europa occidental, Japón o Australia que en regiones con una cultura agrícola marcada como China, Europa del este, Asia central y países africanos en vías de desarrollo. En 1999 se realizó un estudio donde se incluyeron niños con edades comprendidas entre 6-7 años y 13-14 años de 56 países distintos ${ }^{1}$. La prevalencia de pacientes con DA entre 6-7 años osciló entre menos de un 2\% (Irán) y un 16\% (Japón y Suecia), mientras que en niños de entre 13 y 14 años, las cifras más bajas se observaron en Albania (menos de un 1\%) y las más altas en Nigeria (17\%). En ge- 
neral, los países con mayor prevalencia de DA fueron Australia y el norte de Europa; en contraposición, Asia central (China) y Europa central y del este fueron los países con menor prevalencia. Los autores también observaron que individuos de una misma raza presentaban cifras muy dispares en función del país donde residían, dato que resalta la importancia de los factores ambientales en el desarrollo de la DA. En este mismo sentido, también se ha observado que los individuos de una determinada etnia que emigran a otros países, presentan la misma prevalencia de DA que la del país que les acoge $e^{3}$. Estudios sobre la inmigración y el desarrollo de DA apoyan la hipótesis de que son los factores ambientales y el estilo de vida, más que las diferencias raciales, los que juegan un papel importante en el desarrollo de la DA.

En cuanto a España, en el año 2005 se realizó un estudio retrospectivo de casos y controles en el que se incluyeron 4.243 niños menores de 14 años afectados de DA y un grupo control de 978 individuos sanos ${ }^{2}$. En este trabajo se observó que en las zonas de España con clima más frío (cantábrico y continental) los brotes fueron más frecuentes que en las zonas más cálidas (zona de levante y suroeste peninsular). Estos datos fueron similares a los de otro estudio ${ }^{4}$, en el que se incluían 12 países europeos donde también se observó una correlación negativa entre la temperatura media anual y la prevalencia de los síntomas de DA. Finalmente, otro trabajo español más reciente ${ }^{5}$ incluyó 28.394 niños españoles con edades comprendidas entre 6 y 7 años pertenecientes a tres regiones climáticas diferentes, observándose diferencias estadísticamente significativas entre las tres zonas geográficas (atlántico, mediterráneo o continental) con prevalencias del 32,9\%, 28,3\% y $31,2 \%$ respectivamente, así como una asociación positiva entre la DA, la precipitación y el grado de humedad de cada zona, y una asociación negativa entre la DA, la temperatura y el número de horas solares anuales. En conclusión, y al igual que los dos estudios anteriores, resultó que la DA era significativamente dependiente de las condiciones meteorológicas, y, por tanto, del entorno.

\section{Diferencias raciales}

Diversos estudios han tratado de evaluar la importancia del origen étnico en el desarrollo de la DA. Así, un estudio ${ }^{6}$ reveló que sobre una prevalencia global del 3,2\% en pacientes de San Diego (California), un 3,7\% pertenecían a la raza negra, un $8,5 \%$ 
eran filipinos, un $2 \%$ suramericanos, un $2,8 \%$ caucásicos y un $5,6 \%$ asiáticos. En el Reino Unido, otros autores observaron que la prevalencia de DA en la raza negra duplicaba la de la raza blanca $(16,3 \% \text { vs. } 8,7 \%)^{7}$. Estos resultados indican que pueden existir diferencias étnicas significativas, pero siempre sobre la base genética y ambiental de cada individuo.

\section{Agregación familiar}

Con mucha frecuencia, los niños con DA presentan familiares de primer grado afectados, y se ha demostrado que los gemelos monocigóticos tienen una probabilidad de afectación simultánea del $77 \%$, frente al $15 \%$ de los gemelos dicigóticos ${ }^{8}$. Se trata de una herencia poligénica todavía no bien comprendi$\mathrm{da}$, en la que se han involucrado diversos genes. El asma y la rinitis en uno de los progenitores parece ser un factor predisponente de menor trascendencia en el desarrollo de la DA, lo cual sugiere que la DA posee "genes propios"?

\section{Avances en fisiopatología: hallazgos inmunopatológicos y genéticos recientes}

Hay dos hipótesis que tratan de explicar la patogenia de la DA. Una sostiene que el defecto primario reside en una alteración inmunológica que provoca la sensibilización del individuo mediada por la IgE, siendo la alteración de la función barrera una mera consecuencia de la inflamación local. Según la otra hipótesis, la anomalía intrínseca residiría en las células epiteliales, y los trastornos inmunológicos serían un epifenómeno. En todo caso, la patogénesis de la DA es compleja y multifactorial, por lo que para entender su fisiopatología hay que tener en cuenta simultáneamente la predisposición genética, la debilidad de la barrera cutánea, la alteración del sistema inmune y el papel de las sobreinfecciones microbianas, factores que analizaremos a continuación.

\section{Factores genéticos}

La DA es una enfermedad genética muy compleja en la que se han detectado anomalías genéticas en dos grupos mayores de locus: locus que codifican proteínas estructurales del epitelio, y locus que codifican elementos mayores del sistema inmunológico. Así, a partir del año 2000 se han descrito múltiples locus implicados en la patogénesis de la DA, denominados ATOD1 (3q21), ATOD2 (1q21), ATOD3 y ATOD4 (20p), ATOD5 (13q12-q14), у ATOD6 (5q31-q33) $)^{10-12}$. En el cr1q21 (ATOD2) se localiza la familia de locus del com- 
plejo de diferenciación epitelial, entre la que se encuentra la filagrina, una proteína epidérmica fundamental en la creación de los queratinocitos ${ }^{13}$, mientras que en el cr5q31-33 (ATOD6) reside un área del genoma que participa en la síntesis de citoquinas relacionadas con la regulación de las IgE, es decir, las interleukinas $4,5,12$ y 13 y el factor de estimulación de las colonias de granulocitos-macrófagos $(\mathrm{GM}-\mathrm{CSF})^{14}$. Adicionalmente, en el año 2007, un estudio demostró que los pacientes con DA presentan una expresión anormal del COL29A1 (un tipo de colágeno que participa en la adhesión celular y la organización arquitectural de los tejidos) en la epidermis, lo cual apoya la implicación de esta molécula en la patogenia de la $\mathrm{DA}^{15}$. De momento no hay resultados genéticos concluyentes, de modo que parece que el fenotipo atópico resulta de la interacción de múltiples genes por un mecanismo todavía no esclarecido.

\section{Alteración de la barrera cutánea}

Está demostrado que los pacientes con DA presentan una disfunción en la barrera epidérmica. La medición de esta deficiencia se realiza mediante la cuantificación de la pérdida de agua transepidérmica $(T E W L)^{16}$, la cual se encuentra invariablemente aumentada en estos pacientes.

Las causas de la alteración de la barrera epidérmica son múltiples. Cuando se describieron las mutaciones de la filagrina en el año 2006, se le dio un papel fundamental en la fisiopatogenia de la DA. Solo el $30 \%$ de los pacientes con DA presentan mutaciones en el gen de la filagrina, mientras que el aumento de la TEWL se observa en casi el $100 \%$ de pacientes atópicos con enfermedad activa $^{17}$. Por otro lado, se ha visto que los niveles de filagrina pueden ser también modulados a la baja por medio de citoquinas Th2 IL-4 e IL-13, por lo que es posible que el fallo en la función de las filagrinas sea inducido además de genético ${ }^{18}$.

Otras causas de disfunción de la barrera epidérmica incluyen una mala regulación de los genes epidérmicos que codifican proteasas y antiproteasas ${ }^{19,20}$ (proteínas que degradan las uniones intercelulares y promueven la descamación cutánea normal), la pérdida de la integridad de las tight junctions (otros mecanismos especializados de la unión intercelular), la pérdida de adhesión entre los desmosomas ${ }^{18}$, o la alteración en la producción de ceramidas (lípidos epidérmicos). Todos estos fenómenos pueden empeorar con factores como la co- 
lonización microbiana, el rascado y la exposición a alergenos portadores de proteasas, lo cual sugiere que los pacientes con DA tienen un defecto en la función barrera con una base tanto genética como adquirida ${ }^{21}$.

\section{Mecanismos inmunopatológicos:} la inmunidad innata y su relación con la inmunidad adquirida

Es un hecho evidente en la práctica clínica que los niños atópicos tienen un riesgo aumentado de sufrir infecciones bacterianas, virales y fúngicas. Los datos actuales sugieren que la susceptibilidad a las infecciones cutáneas es debida principalmente a anormalidades del sistema inmune innato, que en condiciones normales actúa como la primera línea defensiva ante las infecciones. Las células epiteliales o queratinocitos poseen un tipo de receptores denominado toll-like receptors (TLR) que reconocen determinadas estructuras microbianas y activan mecanismos de inmunidad innata como la producción de péptidos antimicrobianos (PAM), incluyendo defensinas $y$ catecilidinas. El papel de los PAM es fundamental para la respuesta inmune innata debido a su amplio espectro de actividad contra patógenos como el estafilococo áureo, el virus del herpes simple, los poxvirus, el virus vaccinia y algunas especies de Malassezia ${ }^{18}$. Por otro lado, los PAM estimulan respuestas inmunes funcionando como factores quimiotácticos de células dendríticas, polimorfonucleares y células $T$, e inducen una recuperación más rápida de la función barrera. Por consiguiente, cualquier alteración en la expresión o señalización de los TLR disminuye la efectividad del sistema inmune innato y aumenta la susceptibilidad a las infecciones. Además de disminuir la producción de péptidos antimicrobianos, el déficit de TLR promueve la respuesta inflamatoria mediada por los linfocitos Th2, los cuales aumentan la producción de citoquinas y disminuyen la expresión de la filagrina, una proteína epidérmica que participa en la integridad de la barrera cutánea. A su vez, las citoquinas producidas por los linfocitos Th2 alteran retrógradamente la expresión de TLR, empeorando aún más la deficiente respuesta de los PAM. Se sabe que los PAM son deficientes en la piel de los pacientes con DA, lo cual apoya la importancia de su función ${ }^{22}$ y justifica la extensa colonización de la piel sana y lesional por estafilococo dorado y hongos del género Malassezia. Hasta el momento se han detectado polimorfismos en algunos de estos TLR, especialmente el TLR2, que parecen explicar un déficit funcional de los mismos ${ }^{23}$. 
Estudios recientes demuestran que la inmunidad adquirida puede regular la respuesta inmune innata y viceversa. Así, la inmunidad adquirida sería capaz de minimizar el daño tisular, a la vez que la respuesta primaria innata modularía la respuesta inmune adquirida de forma sincrónica y sin periodo de latencia ${ }^{24}$. Según la teoría de la higiene, los niños con más higiene carecerían de una estimulación potente del sistema inmune, lo cual redundaría en una escasa respuesta Th1 y en un predominio de las vías proalérgicas Th2, responsables del inicio de la cascada atópica (asma y rinitis) ${ }^{25-27}$. Esta teoría ha llevado a investigar formas de mejorar la respuesta Th1 en la infancia, sobre todo con la administración de alimentos probióticos vía digestiva. Aunque existían resultados dispares, el metaanálisis más reciente ${ }^{28}$ no aporta conclusiones a favor del uso de alimentos probióticos.

Otro de los factores inmunológicos clásicamente relacionados con el desarrollo de la DA es el aumento de la IgE. Sin embargo, su papel exacto, probable consecuencia del desequilibrio Th2 (que favorece diferenciación del fenotipo de células plasmáticas hacia la producción de lgE) no se conoce apenas o se limita a hipótesis especulativas en ausencia de ensayos bien diseñados centrados en la $\lg E^{29}$. De hecho, en las fases iniciales de la DA no se detecta sensibilización alérgica mediada por lgE, y en algunos casos ni siquiera en el transcurso de la enfermedad $^{30}$. Por otra parte, en el suero de algunos pacientes se han detectado IgE específicas contra las propias estructuras epiteliales del individuo, y se cree que estos autoanticuerpos podrían perpetuar la inflamación cutánea, por lo que la DA estaría en una frontera entre la sensibilización alérgica y la autoinmunidad ${ }^{31}$.

Por último, en los últimos tiempos se ha demostrado la influencia de la vitamina $D$ en la expresión de PAM en los queratinocitos $^{32}$. Recientes estudios han demostrado que un déficit en la acción de 1,25dihidroxi-vitamina $D$ conlleva una diferenciación epidérmica más lenta y una recuperación de la función barrera aminorada. Además, la vitamina $D_{3}$ ha demostrado también actividad antimicrobiana contra estafilococo áureo ${ }^{33}$, y se han detectado algunos polimorfismos en el receptor de vitamina $D_{3}$ en muchas enfermedades inflamatorias, entre ellas la DA.

En conclusión, en la DA existen defectos del sistema inmune que incluyen defectos en la función barrera, polimorfismos genéticos en los TLR y disminución de PAMs. Todos estos factores se relacionan entre sí y a su vez con la respuesta inmune adquirida, responsable 
última de la elevación de la IgE. Algunos de estos defectos preceden a la enfermedad clínicamente detectada y otros se desarrollan como consecuencia del desarrollo de esta, pero no parece que haya un criterio único para aplicar a la mayoría de los casos, puesto que se podría llegar al mismo cuadro clínico con distinta combinación de factores inmunológicos y genéticos.

\section{Diagnóstico de la dermatitis atópica}

No existe ninguna prueba de laboratorio específica para el diagnóstico de la DA, por lo que, en la práctica, las claves diagnósticas dependerán de las manifestaciones cutáneas y la historia clínica del paciente. Indudablemente, el picor y la recurrencia son los datos clínicos esenciales de la DA. Existen, además, otra serie de manifestaciones menos típicas muy indicativas de DA, las cuales fueron sistematizadas por Hanifin y Rajka en $1980^{34}$ (tabla I). Estos autores idearon unos conocidos criterios "mayores" y otros "menores" que los pacientes sospechosos de DA deberían cumplir como mínimo para poder ser diagnosticado de la enfermedad. Aunque ciertamente útil para estudios epidemiológicos, estos criterios presuponen una cierta pericia diagnóstica por parte del examinador ("no todo es DA"), pueden no estar presentes en el momento de la visita, y en ocasiones se observan en la población normal. En 1994, un grupo de autores británicos propusieron otros criterios menos detallados pero más sencillos de utilizar ${ }^{35}$ (tabla II) en el proceso diagnóstico (figura 1). En esencia, la DA es un cuadro pruriginoso, crónico y recurrente que debuta en los primeros años de la vida y afecta localizaciones típicas. En la primera infancia, las lesiones asientan en la cara, el cuello y las superficies de extensión de las extremidades; tras el primer año de vida, se afectan específicamente los pliegues flexurales de brazos y piernas, aunque también puede haber lesiones en otras partes del cuerpo. En niños mayores, es frecuente la afectación facial y la liquenificación de las lesiones preexistentes (engrosamiento de la piel inducido por el rascado permanente). El picor es constante y puede ser incoercible, ya que los antihistamínicos no son eficaces para reducirlo. Se cree que no está mediado por la histamina, sino que es la interleuquina 31 el factor etiopatogénico fundamenta $^{31}$. Habitualmente, la DA no requiere exploraciones complementarias, y nosotros no solicitamos rutinariamente estudios hematológicos ni pruebas alergológicas para descartar sensibilización o alimentaria, sino sólo en casos seleccionados). Teniendo en cuenta que los nive- 
les de IgE no están invariablemente elevados en la DA y que la sensibilización alérgica mediada por IgE es rara antes del primer año de vida, su cuantificación no parece un dato imprescindible.

El diagnóstico de los cuadros típicos de DA suele ser inmediato, pero en algunas ocasiones puede ser necesaria la colaboración del dermatólogo. Aunque actualmente no existe un protocolo general de derivación para aquellos pacientes con DA que precisan atención especializada, unos criterios de derivación adecuados podrían ser los siguientes:

Tabla I. Criterios diagnósticos de Hanifin y Rajka para la dermatitis atópica (DA) ${ }^{34}$

Criterios mayores: debe tener 3 o más:

1. Prurito

2. Distribución y morfología típica

- Eccema flexural en adultos

- Zona extensora y facial en niños

3. Dermatitis crónica recidivante

4. Historia personal o familiar de atopia (asma, rinitis alérgica, DA)

Criterios menores: deben tener 3 o más de:

1. Xerosis

2. Ictiosis, hiperlinearidad palmar o queratosis pilar

3. Reactividad a pruebas cutáneas inmediata (tipo 1)

4. IgE sérico elevado

5. Comienzo a temprana edad

6. Tendencia a infecciones cutáneas (especialmente $S$. aureus y herpes simplex) o defecto en la inmunidad mediada por células

7. Tendencia a dermatitis inespecífica en manos y pies

8. Eccema del pezón

9. Queilitis

10. Conjuntivitis recurrente

11. Pliegue infraorbitario de Dennie-Morgan

12. Queratocono

13. Catarata anterior subcapsular

14. Oscurecimiento orbitario (ojeras)

15. Eritema o palidez facial

16. Pitiriasis alba

17. Pliegues anteriores del cuello

18. Prurito al sudar (hipersudoración)

19. Intolerancia a lanas y solventes orgánicos

20. Acentuación perifolicular

21. Intolerancia a alimentos

22. Curso influenciado por factores ambientales o emocionales

23. Dermografismo blanco 
1. Confirmación diagnóstica.

2. Valoración de otros procesos dermatológicos asociados que requieran pruebas específicas (ej: posible dermatitis alérgica de contacto asociada).

3. Formas graves que afecten a una parte importante de la superficie corporal.

4. Formas rebeldes al tratamiento (pacientes que tras un mes de tra- tamiento adecuado no presentan mejoría clínica).

5. Pacientes con infecciones cutáneas recurrentes.

¿Es posible predecir el curso de la enfermedad? Implicaciones del tratamiento en la infancia

El curso y el pronóstico de la DA son muy variables, con fases alternantes aparentemente inexplicables de mejo-

Figura 1. Algoritmo diagnóstico de la dermatitis atópica (DA).

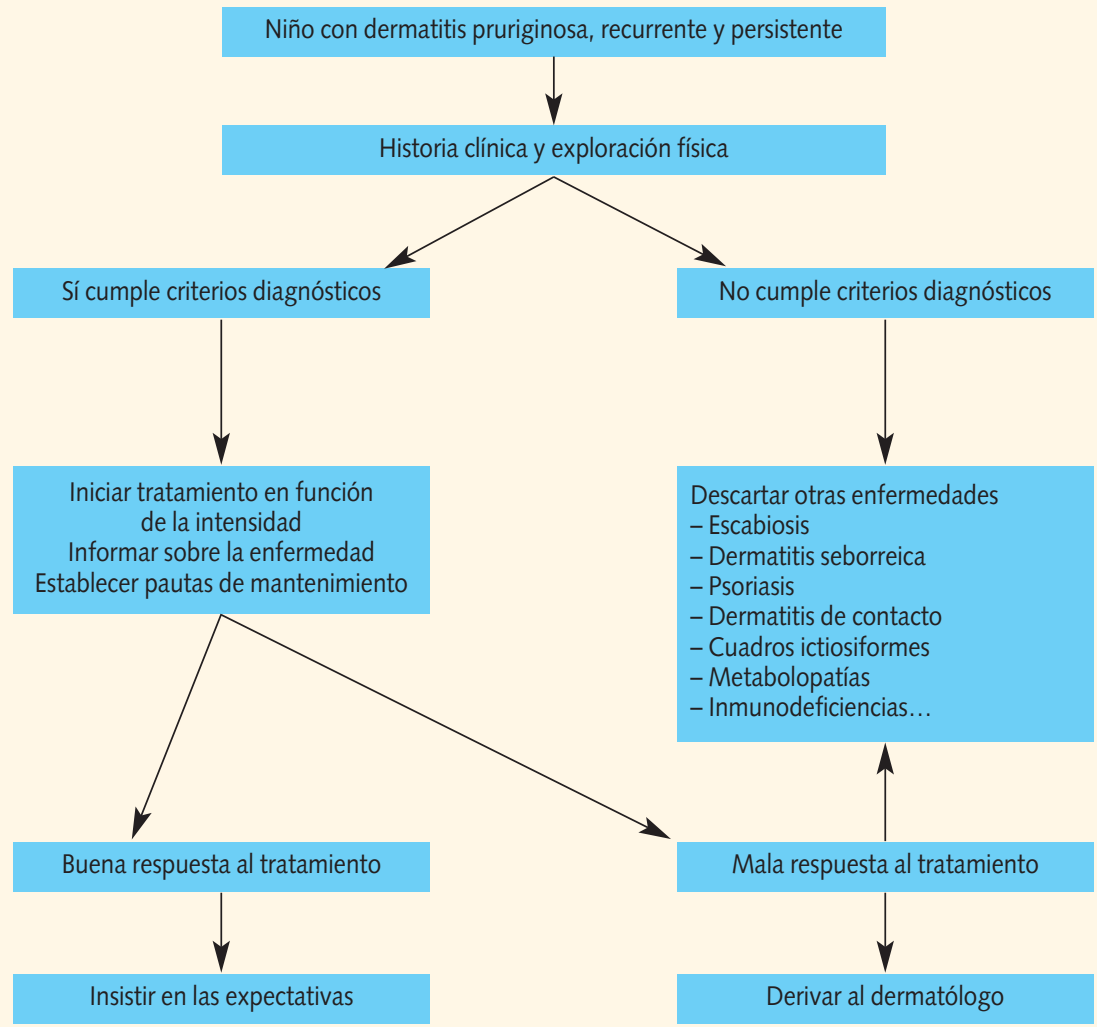


ría y empeoramiento. La mayoría de los niños curan en los primeros años de la vida, pero otros alcanzan la pubertad con importante afectación, sin que fuera posible predecirlo de antemano. En un estudio de seguimiento a largo plazo (16,9 $\pm 2,9$ años) publicado en el año $2006^{36}$, se observó que al cabo del tiempo se habían curado el $60 \%$ de los pacientes con DA, el $34 \%$ habían desarrollado asma, y el $56,7 \%$ rinoconjuntivitis. La curación había ocurrido antes si la intensidad de la enfermedad cutánea era menor $(6,0 \pm$ 3,5 años frente a 5,5 $\pm 3,9$ años respectivamente). El tiempo de duración de la enfermedad fue significativamente más prolongado cuando se asociaba alergia al huevo, así como el porcentaje de pacientes que desarrolló asma y/o rinoconjuntivitis. Según estos datos, la intensidad de la DA y la presencia concomitante de alergia al huevo son factores pronósticos desfavorables.

Sin embargo, aunque no se puede predecir el curso de la enfermedad cutánea, parece que su tratamiento sí puede tener implicaciones en el desarrollo de otras manifestaciones atópicas. El espectro clínico de la atopia incluye el asma, la rinitis, la alergia alimentaria y la DA. Se denomina marcha atópica al desarrollo secuencial de estos cuadros clínicos a lo largo de la edad pediátrica. Para algunos autores, los síntomas de DA anticiparían el desarrollo de rinitis o asma alérgico,

Tabla II. Criterios diagnósticos de la dermatitis atópica (DA) (grupo británico) ${ }^{35}$

Manifestación esencial: dermatitis pruriginosa (o relato de rascado por los padres)

Manifestaciones asociadas (al menos tres)

1. Historia de afectación de pliegues cubitales, poplíteos, tobillos o cuello (y mejillas en niños menores de 10 años)

2. Historia personal de asma y/o fiebre del heno, o historia familiar de atopia en familiares de primer grado en niños menores de 4 años

3. Historia de sequedad cutánea generalizada en el último año

4. Eccema flexular visible (o en mejillas, frente y región extensora de extremidades en niños menores de 4 años

5. Inicio antes de los 2 años (no válido si el niño es menor de 4 años)

Condiciones de exclusión: el diagnóstico de DA requiere la exclusión de otras enfermedades como la escabiosis, la dermatitis seborreica, la dermatitis alérgica de contacto, las ictiosis, la psoriasis y las inmunodeficiencias. 
sugiriendo que la DA sería el punto de partida para la enfermedad alérgica futura. Por tanto, la reparación de la barrera cutánea con el tratamiento impediría la sensibilización del individuo y la afectación de otros órganos como el pulmón o las mucosas.

Varios estudios apoyan la teoría de la marcha atópica ${ }^{37,38}$. En ellos se observa mayor prevalencia de DA que de rinitis o asma en los primeros años de vida. La tendencia de la DA es hacia la curación o mejoría en la mayoría de los casos, mientras que con el paso de los años, aumenta la prevalencia de asma o rinitis alérgica. De esta mane$\mathrm{ra}$, parece que la DA en la infancia precoz podría ser un factor de riesgo para el desarrollo de asma ${ }^{37}$ y rinitis ${ }^{39}$, ya que en muchos casos la clínica cutánea precede al inicio de las manifestaciones asmáticas. Sin embargo, la teoría de la marcha atópica ha sido criticada por algunos autores ${ }^{40}$, que consideran que la progresión no es exactamente la misma en todos los pacientes. Barberio y cols. realizaron un estudio con 629 niños asmáticos en el cual se observó, a lo largo de un periodo de seguimiento de 9 años, que el $20 \%$ de los pacientes desarrollaron una DA, planteando la opción de que, recíprocamente, el asma pudiera ser un factor de riesgo para el desarrollo de DA.

\section{Prevención de la dermatitis atópica}

Las estrategias para la prevención secundaria de exacerbaciones y síntomas de la DA han progresado en los últimos años, pero lamentablemente, estos avances no se han producido en el ámbito de la prevención primaria. Dado que los factores genéticos son inmodificables, las estrategias profilácticas se dirigen, con mayor o menor éxito, a los factores ambientales.

\section{Dieta}

Los niños pequeños sufren una inmadurez relativa del tracto gastrointestinal, por lo que puede observarse intolerancia a determinados alimentos altamente antigénicos como la leche de vaca o el huevo. Desafortunadamente, los estudios realizados con dietas sin estos alimentos no han podido demostrar su eficacia en la prevención primaria de DA salvo en casos muy seleccionados. Sin embargo, los pacientes en los que se sospeche alergia alimentaria (confirmada con valores de IgE específica frente a dicho alimento), podrían beneficiarse de una dieta restrictiva. En la actualidad no existen otros indicadores específicos de alergias alimentarias, por lo que la acti- 
tud terapéutica se apoyaría en gran medida en la historia clínica, con la considerable limitación a la hora de establecer qué alimento es el causante de las exacerbaciones.

El efecto preventivo de la lactancia materna sobre la atopia sigue siendo objeto de controversia ${ }^{41,42}$; en cualquier caso, su recomendación durante los primeros 4 meses está justificada por otros aspectos beneficiosos de la misma. Las dietas restrictivas de la madre durante el embarazo y la lactancia tienen escaso efecto preventivo, y no deben recomendarse sistemáticamente. Tampoco está claro que las fórmulas hidrolizadas lo tengan, ni que el retraso de la introducción de los alimentos alergénicos más allá del $4 .^{\circ}-6{ }^{\circ}$ mes de vida sea beneficioso ${ }^{43}$.

\section{Entorno}

Como ya se ha comentado anteriormente, la exposición de la madre al tabaco durante el embarazo (ya sea de forma pasiva o activa) debe limitarse con el fin de disminuir el riesgo de atopia en el niño $0^{41,44}$. Se ha encontrado una relación dosis-respuesta entre la exposición al tabaco en los primeros meses de vida y la sensibilización mediada por $\lg \mathrm{E}^{45}$.

La sensibilización a ácaros del polvo es especialmente frecuente en pacientes con DA. Sin embargo, la eliminación aislada de estos ácaros del entorno del niño no ha demostrado un efecto beneficioso ${ }^{46}$. No obstante, un gran estudio que combinó la eliminación de ácaros con dietas restrictivas en niños de alto riesgo demostró que estas medidas pueden ser preventivas frente al desarrollo de sensibilización alérgica en este grupo ${ }^{47}$.

\section{Higiene}

Numerosos estudios indican que un entorno lleno de alergenos puede tener un efecto protector frente al desarrollo de atopia ${ }^{25}$. La prevalencia de rinoconjunitivitis alérgica es considerablemente menor en áreas rurales que en áreas urbanas. No se conoce el mecanismo exacto por el cual se produce esta protección, aunque se vincula una supresión de la vía Th2 (responsable de la inmunidad innata implicada en la atopia) a favor de la Th1 (relacionada con inmunidad adquirida). También se ha observado que las endotoxinas procedentes de bacterias gram negativas son más abundantes en colchones de áreas rurales ${ }^{48}$, pero los estudios dirigidos a determinar el efecto preventivo de la exposición a estas endotoxinas han arrojado resultados controvertidos ${ }^{49}$. 


\section{Probióticos}

Metaanálisis realizados recientemente han concluido que la ingesta de prebióticos (lactobacillus y bifidobacterias) tanto prenatal como posnatalmente podrían ser una medida efectiva para la prevención de DA en recién nacidos de riesgo, pero no ha podido demostrarse efecto curativo de los mismos ${ }^{28}$.

En conclusión, dado que el mecanismo patogenético de la DA no está completamente dilucidado, resulta difícil esclarecer qué factores determinan el desarrollo de la enfermedad, y, por tan- to, no está claro si la exposición a factores potencialmente sensibilizantes como los alimentos o los alergenos ambientales (pelo de gato, los pólenes, los ácaros del polvo -específicamente $D$. pteronyssinus- o incluso el tabaco), pueden ser considerados factores de riesgo para el desarrollo de la enfermedad cutánea. Tampoco las intervenciones sobre la alimentación parecen mejorar el pronóstico de la DA de manera significativa, por lo que no se recomienda establecer protocolos alimentarios rutinariamente.

\section{Bibliografía}

1. Williams $H$, Robertson $C$, Stewart A, it-Khaled N, Anabwani G, Anderson R, et al. Worldwide variations in the prevalence of symptoms of atopic eczema in the International Study of Asthma and Allergies in Childhood. J Allergy Clin Immunol. 1999;103 (1 Pt 1):125-38.

2. Blanco QA, az Castella JM, Balana VM, Valveny $L N$. Factores de riesgo de dermatitis atópica y su prevalencia en España (estudio ELIHO). An Pediatr (Barc). 2005;63:480-8.

3. Rottem M, Szyper-Kravitz $M$, Shoenfeld $Y$. Atopy and asthma in migrants. Int Arch Allergy Immunol. 2005;136:198-204.

4. Weiland SK, Husing A, Strachan DP, Rzehak $P$, Pearce N. Climate and the prevalence of symptoms of asthma, allergic rhinitis, and atopic eczema in children. Occup Environ Med. 2004;61:609-15.

5. Suárez-Varela MM, García-Marcos AL, Kogan MD, González AL, Gimeno AM, Ontoso IA, et al. Climate and prevalence of atopic eczema in 6- to 7-year-old school children in Spain. ISAAC phase III. Int J Biometeorol. 2008;52:833-40.

6. Baker R. Incidence of atopic dermatitis and eczema by ethnic group seen within a general pediatric practice. De Permanente Journal. 1999;3:31-2.

7. Williams $H C$, Pembroke AC, Forsdyke $H$, Boodoo G, Hay RJ, Burney PG. London-born black Caribbean children are at increased risk of atopic dermatitis. J Am Acad Dermatol. 1995;32 (2 Pt 1):212-7.

8. Schultz Larsen FV, Holm NV. Atopic dermatitis in a population based twin series. Concordance rates and heritability estimation. Acta Derm Venereol Suppl. 1985;114:59.

9. Morar N, Willis-Owen SA, Moffatt MF, Cookson WO. The genetics of atopic dermatitis. J Allergy Clin Immunol. 2006;118:24-34. 
10. Lee YA, Wahn U, Kehrt R, Tarani L, Businco L, Gustafsson D, et al. A major susceptibility locus for atopic dermatitis maps to chromosome 3q21. Nat Genet. 2000;26:470-3.

11. Beyer K, Nickel R, Freidhoff L, Bjorksten B, Huang SK, Barnes KC, et al. Association and linkage of atopic dermatitis with chromosome 13q12-14 and 5q31-33 markers. J Invest Dermatol. 2000;115:906-8.

12. Cookson WO, Ubhi B, Lawrence R, Abecasis GR, Walley AJ, Cox HE, et al. Genetic linkage of childhood atopic dermatitis to psoriasis susceptibility loci. Nat Genet. 2001;27:372-3.

13. Cookson W. The immunogenetics of asthma and eczema: a new focus on the epithelium. Nat Rev Immunol. 2004;4:978-88.

14. Hoffjan S, Epplen JT. The genetics of atopic dermatitis: recent findings and future options. J Mol Med. 2005;83:682-92.

15. Soderhall C, Marenholz I, Kerscher T, Ruschendorf F, Esparza-Gordillo J, Worm M, et al. Variants in a novel epidermal collagen gene (COL29A1) are associated with atopic dermatitis. PLoS Biol. 2007;5:e242.

16. Werner $Y$, Lindberg $M$. Transepidermal water loss in dry and clinically normal skin in patients with atopic dermatitis. Acta Derm Venereol. 1985;65:102-5.

17. Palmer CN, Irvine AD, Terron-Kwiatkowski A, Zhao Y, Liao H, Lee SP, et al. Common lossof-function variants of the epidermal barrier protein filaggrin are a major predisposing factor for atopic dermatitis. Nat Genet. 2006;38:441-6.

18. De BA, Agnihothri R, McGirt LY, Bankova LG, Beck LA. Atopic dermatitis: a disease caused by innate immune defects? J Invest Dermatol. 2009;129:14-30.

19. Nishio $Y$, Noguchi E, Shibasaki $M$, Kamioka $M$, Ichikawa $E$, Ichikawa $K$, et al. Association between polymorphisms in the SPINK5 gene and atopic dermatitis in the Japanese. Genes Immun. 2003;4:515-7.

20. Vasilopoulos Y, Cork MJ, Murphy R, Williams HC, Robinson DA, Duff GW, et al. Genetic association between an AACC insertion in the 3'UTR of the stratum corneum chymotryptic enzyme gene and atopic dermatitis. J Invest Dermatol. 2004;123:62-6.

21. Kurahashi R, Hatano Y, Katagiri K. IL-4 suppresses the recovery of cutaneous permeability barrier functions in vivo. J Invest Dermatol. 2008;128:1329-31.

22. Michaelsson G. Decreased phagocytic capacity of the neutrophil leucocytes in patients with atopic dermatitis. Acta Derm Venereol. 1973;53:279-82.

23. Bochud PY, Magaret AS, Koelle DM, Aderem A, Wald A. Polymorphisms in TLR2 are associated with increased viral shedding and lesional rate in patients with genital herpes simplex virus Type 2 infection. J Infect Dis. 2007;196:505-9.

24. Lu J, Teh C, Kishore U, Reid KB. Collectins and ficolins: sugar pattern recognition molecules of the mammalian innate immune system. Biochim Biophys Acta. 2002;1572:387-400.

25. Chinen J, Shearer WT. Advances in basic and clinical immunology in 2007. J Allergy Clin Immunol. 2008;122:36-41.

26. Liu AH, Leung DY. Renaissance of the hygiene hypothesis. J Allergy Clin Immunol. 2006;117:1063-6.

27. Schaub B, Lauener R, von ME. The many faces of the hygiene hypothesis. J Allergy Clin Immunol. 2006;117:969-77.

28. Lee J, Seto D, Bielory L. Meta-analysis of clinical trials of probiotics for prevention and treatment of pediatric atopic dermatitis. J Allergy Clin Immunol. 2008;121:116-21.

29. Elias PM, Hatano Y, Williams ML. Basis for the barrier abnormality in atopic dermatitis: out- 
side-inside-outside pathogenic mechanisms. J Allergy Clin Immunol. 2008;121:1337-43.

30. Novak N, Bieber T. Allergic and nonallergic forms of atopic diseases. J Allergy Clin Immunol. 2003;112:252-62.

31. Bieber T. Atopic dermatitis. N Engl J Med. 2008;358:1483-94

32. Gombart AF, Borregaard N, Koeffler HP. Human cathelicidin antimicrobial peptide (CAMP) gene is a direct target of the vitamin D receptor and is strongly up-regulated in myeloid cells by 1,25-dihydroxyvitamin D3. FASEB $J$. 2005;19:1067-77.

33. Liu PT, Stenger S, Li H, Wenzel L, Tan BH, Krutzik SR, et al. Toll-like receptor triggering of a vitamin D-mediated human antimicrobial response. Science. 2006;311(5768):1770-3.

34. Hanifin JM RG. Diagnostic features of atopic dermatitis. Acta Derm Venereol. 1980. 92 (Suppl):44-7.

35. Williams HC, Burney PG, Hay RJ, Archer CB, Shipley MJ, Hunter JJ, et al. The U.K. Working Party's Diagnostic Criteria for Atopic Dermatitis. I. Derivation of a minimum set of discriminators for atopic dermatitis. Br J Dermatol. 1994;131:383-96.

36. Ricci G, Patrizi A, Baldi E, Menna G, Tabanelli $M$, Masi $M$. Long-term follow-up of atopic dermatitis: retrospective analysis of related risk factors and association with concomitant allergic diseases. J Am Acad Dermatol. 2006;55: 765-71.

37. Gustafsson D, Sjoberg O, Foucard T. Development of allergies and asthma in infants and young children with atopic dermatitis: a prospective follow-up to 7 years of age. Allergy. 2000; 55:240-5.

38. Spergel JM, Paller AS. Atopic dermatitis and the atopic march. J Allergy Clin Immunol. 2003;112 (6 Suppl):S118-27.
39. Guerra S, Sherrill DL, Martínez FD, Barbee RA. Rhinitis as an independent risk factor for adult-onset asthma. J Allergy Clin Immunol. 2002;109:419-25.

40. Barberio G, Pajno GB, Vita D, Caminiti L, Canonica GW, Passalacqua G. Does a 'reverse' atopic march exist? Allergy. 2008;63: 1630-2.

41. Schafer T. Prevention of atopic eczema. Evidence based guidelines. Hautarzt. 2005;56: 232-40.

42. Wahn HU. Strategies for atopy prevention. J Nutr .2008;138:S1770-2.

43. Greer FR, Sicherer SH, Burks AW. Effects of early nutritional interventions on the development of atopic disease in infants and children: the role of maternal dietary restriction, breastfeeding, timing of introduction of complementary foods, and hydrolyzed formulas. Pediatrics. 2008;121:183-91.

44. Wang IJ, Hsieh WS, Wu KY, Guo YL, Hwang $\mathrm{YH}$, Jee $\mathrm{SH}$, et al. Effect of gestational smoke exposure on atopic dermatitis in the offspring. Pediatr Allergy Immunol. 2008;19:580-6.

45. Lannero E, Wickman M, van HM, Bergstrom A, Pershagen G, Nordvall L. Exposure to environmental tobacco smoke and sensitisation in children. Thorax. 2008;63:172-6.

46. Horak F Jr., Matthews S, Ihorst G, Arshad $\mathrm{SH}$, Frischer $\mathrm{T}$, Kuehr J, et al. Effect of mite-impermeable mattress encasings and an educational package on the development of allergies in a multinational randomized, controlled birth-cohort study: 24 months results of the Study of Prevention of Allergy in Children in Europe. Clin Exp Allergy. 2004;34:1220-5.

47. Arshad SH, Bateman B, Sadeghnejad A, Gant C, Matthews SM. Prevention of allergic disease during childhood by allergen avoidance: the Isle of Wight prevention study. J Allergy Clin Immunol. 2007;119:307-13. 
48. Schram-Bijkerk D, Doekes G, Douwes J, Boeve M, Riedler J, Ublagger $E$, et al. Bacterial and fungal agents in house dust and wheeze in children: the PARSIFAL study. Clin Exp Allergy. 2005;35:1272-8.
49. Braun-Fahrlander C. Environmental exposure to endotoxin and other microbial products and the decreased risk of childhood atopy: evaluating developments since April 2002. Curr Opin Allergy Clin Immunol. 2003;3:325-9. 